\title{
Editorials
}

\section{Investing in social care to reduce healthcare utilisation}

\section{BACKGROUND}

With increasing age, people are more likely to live with multiple health conditions, be prescribed more medications, and require support from a wide range of services within the health and social care sector. In the context of constrained budgets, it is a challenge for the UK to deliver a welfare system that supports older adults living with frailty within the community. It is certainly not unique across developed countries to be facing this paradox.' The authors' wish to highlight the potential case for investing in the creaking social care system, following recent policy changes promoting spending in adult social care through the Better Care Fund and broader changes in funding streams. ${ }^{2}$

\section{THE PRESSURISED SOCIAL CARE SYSTEM}

The challenges facing the UK's social care services is well documented, with an Age UK report estimating that, in England, 54000 people - or 77 a day - have died while waiting for a care package in the 700 days since the UK government declared in March 2017 that it would publish its social care green paper. ${ }^{3}$ This remains unpublished, with the government now missing five consecutive deadlines. The issue has been brought back into the political limelight after the House of Lords Economic Affairs Committee published their report titled Social Care Funding: Time to End A National Scandal, in July 2019.4 The committee recommended an immediate injection of 8 billion GBP, followed by a further 7 billion GBP a year to extend NHSstyle free personal care to all by $2025 / 2026$, paid for out of general taxation. There is a clear precedent, with free personal care already provided in Scotland for those aged 65 years and over, and younger patients with degenerative neurological conditions.

In the UK, social care is funded and delivered through local authorities. In England, a significant proportion of funding for social care flows from Government on a formula basis, with local councils able to use local taxes in addition to central state funds. Locally delivered social care services

\section{0 people - or 77 a day - have died while waiting for a care package in the 700 days since the UK government declared in March 2017 that it would publish its social care green paper.}

are characterised by significant variability in the levels and type of care services provided, giving local authorities the flexibility to deliver services required for their own locality rather than a centralist approach.

Recent work reported that public social care expenditure in different English councils appears to respond significantly to differences in local levels of need and supply. ${ }^{5}$ It was reassuring to see that the same econometric analyses noted that although political control does play a role in terms of making spending decisions, the overall role was limited. ${ }^{5}$ However, the resilience of different local authorities to central government cuts varies extensively, meaning that variations in local authority service provision may be more vulnerable in deprived areas. ${ }^{6}$

Since 2010, the private sector providing social care has experienced reduced profits and slowing growth.? This has reduced the number of available nursing home beds and domiciliary social care supply. This is in part due to significant reductions in funding to local authorities, leading to fees paid by the state in some areas being below the cost required for a care provider to deliver the service. ${ }^{8}$ Unfortunately, this has meant that people who self-fund for care pay higher prices to off-set losses made by providers for state funded service users. ${ }^{7}$ Private providers report that providing care in some areas is simply not viable, which can lead to extensive delays while awaiting packages of care. ${ }^{9}$

These issues do not only affect individuals, but the family and social support around them. There are an estimated 6.5 million carers in the UK. One in five

\section{"Policymakers should consider that adequate supply of social care services has the potential to reduce demand on secondary care services...}

people aged $50-64$ years are carers, with almost 1.3 million carers aged 65 years or older with their own physical and mental health problems (not infrequently caused or worsened by their caring role). ${ }^{10}$ The 2012 In Sickness and In Health survey of 3400 UK carers about their health and wellbeing was remarkable for noting that $64 \%$ and $50 \%$ of responders felt that their own physical and mental health had been impacted secondary to a lack of practical support and financial support respectively. ${ }^{11}$ Anecdotally, in clinical practice, the impact of delays in packages of care starting, being able to arrange respite care, and admission to nursing and residential homes can be significant on patients and their families.

There is some research providing evidence of a trade-off between the number of hospital beds and the level of social care provision. ${ }^{12,13}$ However, these papers focused on longterm residential care and hospital length of stay, and were performed prior to the recent systematic reductions in social care expenditure and provision.

Therefore, the 2019 systematic review published in Age and Ageing is a timely reminder of the current relationship between the supply of social care to older adults and subsequent utilisation of health care. ${ }^{14}$ Speirs et al selected observational studies from high income countries published after 2000 which explicitly examined the relationship between the availability of social care (including support at home or in care homes with and without nursing support) and healthcare utilisation by adults aged $>60$ years old. A total of 12 studies were included, 10 of which were suitable for metaanalyses. There was variable quality of these studies, with seven being rated 'good' in quality, one 'fair', and four 'poor'.

The authors reported that greater availability of care home beds and higher levels of social care expenditure were associated with a reduction in rates of delayed discharge, and the former was 
also associated with an overall reduction of emergency admissions. However, this relationship did not extend to the homecare sector. Better availability of long-term care beds was associated with shorter length of hospital stay for the entire study population. Finally, and of significant importance for policymakers, there were significant reductions in hospital spend in areas with higher formal social care supply.

\section{COMPASSIONATE COMMUNITIES: COMPLEMENTING FORMAL SOCIAL CARE PROVISION}

More broadly, there have been efforts to enhance informal support mechanisms for patients in the community through programmes such as compassionate communities. ${ }^{15,16}$

Compassionate communities do not take the place of formal social care, rather they work to make the most of supportive networks of family, friends, and neighbours and build networks of support for the routine tasks related to caring. The programme directly links to community groups such as choirs, activity groups, and interest groups where patients can share interests. A recent article reported that developing a compassionate community in Frome, England, reduced unplanned hospital admissions by $14 \%$ in the study area, compared to broader changes in the unplanned admissions rate in the same county of an increase of $28.5 \%{ }^{15}$ This approach may also improve supportive networks and care for adults living with terminal condition.

\section{CONSIDERATIONS FOR POLICYMAKERS}

In the context of a shrinking nursing home market and increasing real terms budgetary pressures, a clear message for policymakers that investing into the social care system can deliver improvements for secondary care services is welcome. Policymakers need a clear understanding of the relationship between social care and the wellbeing and health of older people, and the impact of cuts to social services on other public services. With broader concerns about the increase in mortality associated with reducing social care expenditure, ${ }^{17}$ there is a compelling case for politicians and policymakers to encourage new approaches when addressing the social care question. The new Prime Minister, Boris Johnson, making social care reform a key part of his 10 Downing Street speech back in July 2019, was welcome. However, it is imperative that the Government's planned Green Paper addresses the underlying funding gap and advocates a clear and sustainable funding model. Failure to address social care funding and subsequent delivery of services will put vulnerable older people at risk and increase pressure on the NHS.

\section{CONCLUSION}

The influence of social care provision for older adults on subsequent secondary care utilisation is a policy concern. Policymakers should consider that adequate supply of social care services has the potential to reduce demand on secondary care services, and that urgent work looking at developing a sustainable reform of social care provision is required to support older adults to live the best possible life in the most appropriate place. Models of care can include formal provision of care but broader communitybased change has the opportunity to improve healthcare outcomes. Meanwhile, the wait for the green paper and a concerted government plan continues.

\section{REFERENCES}

1. Barker K, Chair. A new settlement for health and social care. Final report. Commission on the Future of Health and Social Care in England. 2014. https://unw.kingsfund.org.uk/ sites/default/files/field/field_publication_file/ Commission\%20Final\%20\%20interactive.pdf laccessed 29 Nov 2019).

2. O'Donoghue DJ. Spend, spend, spend. British Journal of Renal Medicine 2019; 24(3): 66-67.

3. Age UK. More than 50000 older people have now died waiting in vain for care during the 700 days since the Government first said it would publish a Care Green Paper. 2019 https://www.ageuk.org.uk/latest-press/ articles/2019/february/more-than-50000older-people-have-now-died-waiting-in-vainfor-care-during-the-700-days-since-thegovernment-first-said-it-would-publish-acare-green-paper (accessed 29 Nov 2019).

4. House of Lords. Economic Affairs Committee. 7th Report of Session 2017-19. Social care funding: time to end a national scandal. 2019 https://publications.parliament.uk/pa/ld201719/ Idselect/ldeconaf/392/392.pdf laccessed 29 Nov 2019).

5. Fernandez JL, Forder J. Local variability in longterm care services: local autonomy, exogenous influences and policy spillovers. Health Econ 2015; Suppl 1: 146-157.

6. Gray M, Barford A. The depths of the cuts: the uneven geography of local government austerity. Cambridge Journal of Regions, Economy and Society 2018; 11(3): 541-563

7. Department of Health. Competition and Markets Authority. Care homes market study. 2018. https://www.gov.uk/cma-cases/carehomes-market-study laccessed 29 Nov 2019).

8. File on 4: cut-price care. BBC Radio 42014; Feb 9. https://unw.bbc.co.uk/programmes/

\section{ADDRESS FOR CORRESPONDENCE}

\section{Lloyd D Hughes}

Lomond Practice, Glenwood Health Centre, Napier Road, Glenrothes KY6 1HL, Scotland.

\section{Email: l.hughes5anhs.net}

\section{Lloyd D Hughes,}

GP Registrar; Staff Grade Doctor in Geriatric Medicine, Lomond Practice, Glenwood Health Centre, Glenrothes, Scotland.

\section{Maggie Keeble,}

Care Home GP; Clinical Lead Integrated Care for Older People, South Worcestershire Clinical Commissioning Group, Worcester, Worcestershire, England.

\section{Provenance}

Freely submitted; externally peer reviewed.

\section{Competing interests}

The authors have declared no competing interests.

DOI: https://doi.org/10.3399/bjgp20X707249

b03szh9m (accessed 26 Nov 2019).

9. Rural England. Issues facing providers of social care at home to older rural residents. Rural England research project. 2017. https:// ruralengland.org/wp-content/uploads/2018/01/ Launch-Report-Issues-Facing-Providers-

Social-Care-in-Rural-England.pdf laccessed 29 Nov 2019).

10. Carers UK. Facts about carers. 2019. https:// wnw.carersuk.org/images/Facts_about_ Carers_2019.pdf laccessed 29 Nov 2019).

11. Carers UK. In sickness and in health. 2012. https://www.carersuk.org/for-professionals/ policy/policy-library/in-sickness-and-in-health laccessed 29 Nov 2019).

12. Holmås TH, Islam MK, Kjerstad E. Interdependency between social care and hospital care: the case of hospital length of stay. Eur J Public Health 2013; 23(6): 927-933.

13. Forder J. Long-term care and hospital utilisation by older people: an analysis of substitution rates. Health Econ 2009; 18(11): 1322-1338.

14. Spiers G, Matthews FE, Moffat S, et al. Impact of social care supply on healthcare utilization by older adults: a systematic review and metaanalysis. Age Ageing 2019; 48(1): 57-66.

15. Abel J, Kingston H, Scally A, et al. Reducing emergency hospital admissions: a population health complex intervention of an enhanced model of primary care and compassionate communities. Br J Gen Pract 2018; DOI: https:// doi.org/10.3399/bjgp18X699437.

16. Abel J. Compassionate communities and endof-life care. Clin Med (Lond) 2018; 18(1): 6-8.

17. Watkins J, Wulaningsih W, Da Zhou C, et al. Effects of health and social care spending constraints on mortality in England: a time trend analysis. BMJ Open 2017; 7(11): e017722. 